of adverse events (AEs) and discontinuations due to AEs were similar across groups, though serious AEs occurred more frequently in both tanezumab groups relative to placebo. Two deaths in the $5 \mathrm{mg}$ tanezumab group were deemed unrelated to treatment. The only $\mathrm{AE}$ occurring in $=3 \%$ of patients in any group, and more frequently ( $>1 \%$ difference) in both tanezumab groups relative to placebo, was OA. Total joint replacements (TJR) occurred in $6.7 \%, 7.8 \%$, and $7.0 \%$ of patients in the placebo, tanezumab $2.5 \mathrm{mg}$, and tanezumab $5 \mathrm{mg}$ groups, respectively. Joint safety events, including TJRs, were mostly adjudicated as normal progression of OA (58/79; 73.4\%). Pre-specified joint safety events occurred in $0 \%$ and $2.5 \%(n=14)$ of patients in the placebo and tanezumab $(2.5 \mathrm{mg}=1.8 \% ; 5 \mathrm{mg}$ $=3.2 \%$ ) groups, respectively. These 14 events in the tanezumab groups included rapidly progressive $\mathrm{OA}(2.5 \mathrm{mg} \mathrm{n}=4 ; 5 \mathrm{mg} \mathrm{n}=8)$, subchondral insufficiency fracture $(2.5 \mathrm{mg} n=1)$, and primary osteonecrosis $(5 \mathrm{mg} n=1)$.

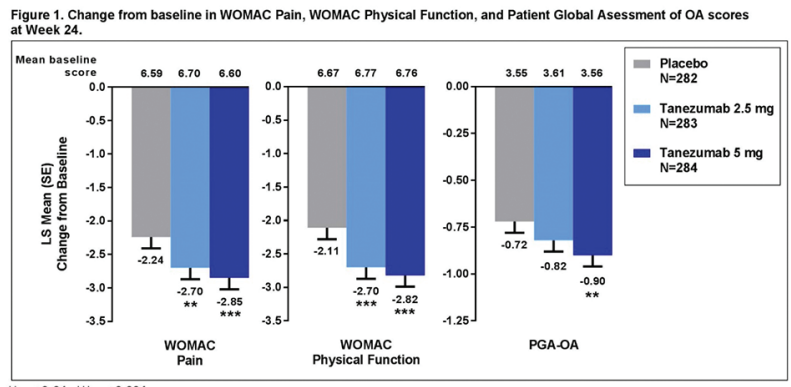

\begin{tabular}{|c|c|c|c|}
\hline $\mathrm{N}(\%)$ of patients & $\begin{array}{l}\text { Placebo } \\
\mathrm{N}=282\end{array}$ & $\begin{array}{c}\text { Tanezumab } 2.5 \mathrm{mg} \\
\mathrm{N}=283\end{array}$ & $\begin{array}{c}\text { Tanezumab } 5 \mathrm{mg} \\
\mathrm{N}=284\end{array}$ \\
\hline AE & $155(55.0)$ & $150(53.0)$ & $162(57.0)$ \\
\hline Serious AE & $3(1.1)$ & $8(2.8)$ & $9(3.2)$ \\
\hline Discontinued study due to $\mathrm{AE}$ & $2(0.7)$ & $5(1.8)$ & $1(0.4)$ \\
\hline Discontinued treatment but continued study & $7(2.5)$ & $3(1.1)$ & $4(1.4)$ \\
\hline \multicolumn{4}{|l|}{ Common AEs ${ }^{a}$} \\
\hline Arthralgia & $34(12.1)$ & $27(9.5)$ & $23(8.1)$ \\
\hline Nasopharyngitis & $25(8.9)$ & $31(11.0)$ & $22(7.7)$ \\
\hline Back pain & $15(5.3)$ & $16(5.7)$ & $17(6.0)$ \\
\hline Headache & $18(6.4)$ & $15(5.3)$ & $14(4.9)$ \\
\hline Osteoarthritis & $5(1.8)$ & $9(3.2)$ & $13(4.6)$ \\
\hline Paraesthesia & $5(1.8)$ & $5(1.8)$ & $12(4.2)$ \\
\hline Influenza & $5(1.8)$ & $5(1.8)$ & $9(3.2)$ \\
\hline Fall & $8(2.8)$ & $12(4.2)$ & $7(2.5)$ \\
\hline Pain in extremity & $7(2.5)$ & $9(3.2)$ & $5(1.8)$ \\
\hline
\end{tabular}

Conclusion: Tanezumab 5 mg significantly improved all co-primary endpoints of pain, physical function, and PGA-OA. Tanezumab $2.5 \mathrm{mg}$ significantly improved pain and physical function, but did not reach significance on PGA-OA. AEs are consistent with previous studies of tanezumab in OA. A similar number of TJRs were reported across groups, though overall joint safety events were more frequent with tanezumab than placebo.

Disclosure of Interests: Francis Berenbaum Grant/research support from: TRB Chemedica (through institution), MSD (through institution), Pfizer (throughinstitution), Consultant for: Novartis, MSD, Pfizer, Lilly, UCB, Abbvie, Roche, Servier, Sanofi-Aventis, Flexion Therapeutics, Expanscience, GSK, Biogen, Nordic, Sandoz, Regeneron, Gilead, Bone Therapeutics, Regulaxis, Peptinov, Paid instructor for: Sandoz, Speakers bureau: Novartis, MSD, Pfizer, Lilly, UCB, Abbvie, Roche, Servier, Sanofi-Aventis, Flexion Therapeutics, Expanscience, GSK, Biogen, Nordic, Sandoz, Regeneron, Gilead, Sandoz, Francisco J. Blanco Grant/research support from: Galapagos NV, Abbvie, Sanofi, Bristol MS, UCB, Novartis, Genentech Inc., Regeneron, Lilly, Celgene, Amgen, Janssen, kiniksa Pharmaceuticals, Ltd., Tedec Meiji., Consultant for: Pfizer, Gebro, Bioiberica, Sanofi., Ali Guermazi Consultant for: AstraZeneca, Pfizer, TissueGene, Galapagos, Roche and MerckSerono., Eric Vignon Consultant for: Pfizer/Eli Lilly, Kenji Miki Speakers bureau: Pfizer, Janssen, Ayumi, Hisamitsu, Takaharu Yamabe Shareholder of: Pfizer, Employee of: Pfizer, Lars Viktrup Shareholder of: Eli Lilly \& Company, Grant/ research support from: Astella, Lundbeck, Coloplast, Employee of: Ciba Geigy, Eli Lilly and Company (currently), Rod Junor Shareholder of: Pfizer, Employee of: Pfizer, William Carey Shareholder of: Pfizer, Employee of: J\&J, Pfizer (currently), Mark Brown Shareholder of: Pfizer Inc, Employee of: Pfizer Inc, Ken Verburg Shareholder of: Pfizer, Employee of: Pfizer, Christine West Shareholder of: Pfizer, Employee of: Pfizer

DOI: 10.1136/annrheumdis-2019-eular.8660

\section{LB0008 \\ THE EFFECT OF HLA-DRB1 RISK ALLELES ON THE CLINICALEFFICACY OF ABATACEPT AND ADALIMUMAB IN SEROPOSITIVE BIOLOGIC-NAÏVE PATIENTSWITH EARLY, MODERATE-TO-SEVERE RA: DATA FROM A HEAD-TO-HEAD SINGLE- BLINDEDTRIAL}

William Rigby ${ }^{1}$, Jane Buckner ${ }^{2}$, Lou Bridges ${ }^{3}$, Marleen $\mathrm{Nys}^{4}$, Sheng Gao ${ }^{5}$, Martin Polinsky ${ }^{5}$, Alyssa Johnsen ${ }^{5}$, Neelanjana Ray ${ }^{5}$, Vivian Bykerk ${ }^{61}$ DartmouthHitchcock Medical Center, Lebanon, United States of America; ${ }^{2}$ Benaroya Research Institute, Seattle, United States of America; ${ }^{3}$ University of Alabama School of Medicine, Birmingham, United States of America; ${ }^{4}$ Bristol-Myers Squibb, Braine-l'Alleud, Belgium; ${ }^{5}$ Bristol-Myers Squibb, Princeton, United States of America; ${ }^{6}$ Hospital for Special Surgery, New York, United States of America

Background: Mechanistic differences between biologics are poorly understood HLA-DRB1 alleles containing the shared epitope (SE), which are strongly associated with RA, are present in $85 \%$ of anti-cyclic citrullinated protein 2 (anti-CCP2) + patients (pts) with RA (Jiang et al. Arthritis Rheumatol 2015). In a prior retrospective exploratory analysis, abatacept (ABA) was more effective in SE+ vs SE- pts (Oryoji et al. Ann Rheum Dis 2017). Head-to-head (H2H) comparisons with other agents are lacking.

Objectives: This $\mathrm{H} 2 \mathrm{H}$, single-blinded trial (NCT02557100) in biologic-naïve pts with early, active RA prospectively explored the relationship between HLA-DRB1 SE and the clinical efficacy of ABA or adalimumab (ADA).

Methods: Adults with early ( $=12$ mths from symptom onset), moderate-to-severe RA (ACR/EULAR 2010 criteria) seropositive for anti-CCP2 (>3x ULN) and RF, were randomised 1:1 to SC ABA 125mg wkly or SC ADA 40mg every 2 wks (both with stable, oral MTX wkly) for 24 wks. Pts were grouped by SE status (+/-) based on HLA-DRB1 genotype (-: no SE allele; $+:=1$ SE allele). Safety was analysed throughout the trial and up to 8 wks post last study drug dose. Clinical efficacy was assessed at Wk24 to determine the proportion of ACR20/50/70 responders in $A B A$ vs $A D A$ arms, and the adjusted mean changes from baseline in DAS28 (CRP), SDAI and CDAI. Treatment (tmt) differences between ABA and ADA in SE + and SE- pts were assessed for ACR20/50/70 responders and DAS28 (CRP) remission at Wk24.

Results: 80 pts were treated: 40 ABA (9 SE-, 30 SE+, 1 SE unknown) and 40 ADA (9 SE-, $31 \mathrm{SE}+$ ). Baseline characteristics were balanced. Mean (SD) age, disease duration and DAS28 (CRP) were 46.0 (14.4) years, $5.5(2.6) \mathrm{mths}$ and 5.2 (1.1), respectively; $75 \%$ were female. No new safety signals were identified. In each arm, related AEs (ABA: 12 [30\%]; ADA: 11 [27.5\%]) and related serious AEs (ABA: $0 ; A D A: 1[2.5 \%])$ were similar. Numerically higher efficacy responses were seen with ABA vs ADA at Wk24 (Table 1). Similar results were observed for DAS28 (CRP), SDAI and CDAI. In SE+ pts, numerically higher efficacy responses were seen with $A B A$ vs $A D A$ at Wk24; $95 \% \mathrm{Cl}$ for estimated tmt differences for ACR20/50/70 responses and DAS28 (CRP) remission did not cross 0 (Figure 1). Conclusion: In this seropositive early RA population, numerically higher efficacy responses were seen with abatacept vs adalimumab after 24wks of tmt, with more pronounced tmt differences in SE+ pts. Results are consistent with a previous

Table 1. Clinical outcomes at Wk24: as-treated analysis population

\begin{tabular}{|c|c|c|c|}
\hline Clinical outcome & $\begin{array}{c}A B A \\
(n=40)\end{array}$ & $\begin{array}{c}\text { ADA } \\
(n=40)\end{array}$ & $\begin{array}{c}\text { Estimate of } \\
\text { difference for } A B A \\
\text { vs } A D A(95 \% \mathrm{Cl})\end{array}$ \\
\hline \multicolumn{4}{|l|}{ ACR responses } \\
\hline ACR20 & $83(67,93)$ & $63(46,77)$ & $20(-3,42)$ \\
\hline ACR50 & $70(54,83)$ & $45(29,62)$ & $25(2,46)$ \\
\hline ACR70 & $48(32,64)$ & $30(17,47)$ & $17.5(-6,39)$ \\
\hline \multicolumn{4}{|l|}{ DAS28 (CRP) } \\
\hline $\begin{array}{l}\text { Adjusted mean } \\
\text { change }^{*}(95 \% \mathrm{Cl})\end{array}$ & $-2.6(-2.9,-2.2)$ & $-2.4(-2.7,-2.1)$ & $0.2(-0.6,0.3)^{\dagger}$ \\
\hline Remission & $48(32,64)$ & $30(17,47)$ & $17.5(-6,39)$ \\
\hline \multicolumn{4}{|l|}{ SDAI } \\
\hline $\begin{array}{l}\text { Adjusted mean } \\
\text { change }^{\star}(95 \% \mathrm{Cl})\end{array}$ & $-27.4(-29.9,-24.9)$ & $-26.1(-28.7,-23.5)$ & $-1(-5,2)^{\dagger}$ \\
\hline Remission & $35(21,52)$ & $23(11,39)$ & $12.5(-11,35)$ \\
\hline \multicolumn{4}{|l|}{ CDAI } \\
\hline $\begin{array}{l}\text { Adjusted mean } \\
\text { change }^{*}(95 \% \mathrm{Cl})\end{array}$ & $-27.1(-29.5,-24.7)$ & $-25.0(-27.5,-22.6)$ & $-2(-5.5,1)^{\dagger}$ \\
\hline
\end{tabular}

Data are $\%(95 \% \mathrm{Cl})$ unless stated otherwise. Estimates of adjusted mean change are from a repeated measures mixed model which includes baseline value, treatment group, time and time by treatment group interaction. Missing values were imputed as non-responders. DAS28 (CRP) remission: DAS28 (CRP) <2.6. SDAl remission: SDAl $\leq 3.3$

*From baseline. ${ }^{\dagger}$ Adjusted mean difference for ABA vs ADA ( $95 \% \mathrm{Cl}$ ).

$A B A=a b a t a c e p t ; A C R 20 / 50 / 70=20 / 50 / 70 \%$ improvement in $A C R$ criteria; $A D A=$ adalimumab 
Figure 1. Clinical outcomes in ABA- vs ADA-treated pts at Wk 24 by SE genotype: as-treated analysis population

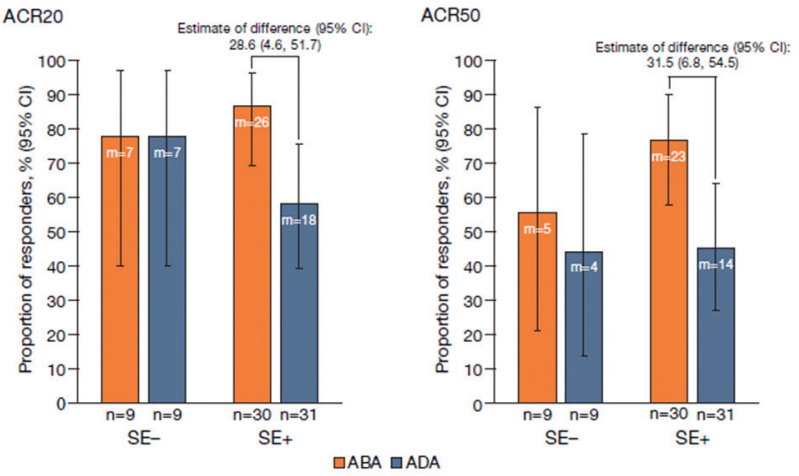

ACR70

DAS28 (CRP) remission
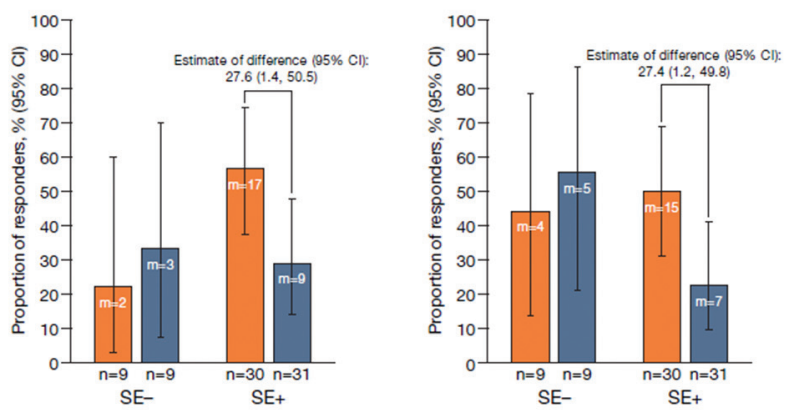

$m$ indicates the number of patients with a response; $n$ indicates the number of patients in the group. Pationts with missing data for efficacy parameters at Week 24 are imputed as non-responders

ADA=adalimumab; SE=shared epitope

study in which greater efficacy was seen with abatacept, but not TNF inhibitors, in anti-CCP2+ vs anti-CCP2- pts with RA (Harrold et al. J Rheumatol 2018).

Acknowledgement: Marianne Peluso (protocol manager); medical writing: Lola Parfitt (Caudex; funding: BMS)

Disclosure of Interests: William Rigby Consultant for: AbbVie, BMS, Genentech and Pfizer, Jane Buckner Grant/research support from: Janssen, BristolMyers Squibb (current); Novo Nordisk, Pfizer, Eli Lilly (past), Consultant for: Bristol-Myers Squibb, Eli Lilly, Lou Bridges: None declared, Marleen Nys Shareholder of: Bristol-Myers Squibb, Employee of: Bristol-Myers Squibb, Sheng Gao Shareholder of: Bristol-Myers Squibb, Employee of: Bristol-Myers Squibb, Martin Polinsky Shareholder of: Bristol-Myers Squibb, Employee of: Bristol-Myers Squibb, Alyssa Johnsen Shareholder of: Bristol-Myers Squibb, Employee of: Bristol-Myers Squibb, Neelanjana Ray Shareholder of: Bristol-Myers Squibb, Employee of: Bristol-Myers Squibb, Vivian Bykerk Grant/research support from: Mallinckrodt, BMS, Crescendo Biosciences, Sanofi/Regeneron., Consultant for: Amgen, Pfizer, UCB, Scipher, Sanofi/Genzyme/Regeneron

DOI: 10.1136/annrheumdis-2019-eular.8668

\section{LB0009 FIRST-IN-HUMAN STUDY OF NOVEL IMPLANTED VAGUS NERVE STIMULATION DEVICE TO TREAT RHEUMATOID ARTHRITIS}

Mark C. Genovese ${ }^{1}$, Norman Gaylis ${ }^{2}$, David Sikes $^{3}$, Alan Kivitz ${ }^{4}$, Diane M Horowitz ${ }^{5}$, Charles Peterfy ${ }^{6}$, Yaakov Levine ${ }^{7}$, David Chernoff ${ }^{7}$. ${ }^{1}$ Stanford University School of Medicine, Stanford, United States of America; ${ }^{2}$ Arthritis and Rheumatic Disease Specialties, Aventura, United States of America; ${ }^{3}$ Florida Medical Clinic, Zephyrhills, United States of America; ${ }^{4}$ Altoona Center for Clinical Research, Duncansville, United States of America; ${ }^{5}$ Northwell Health, Great Neck, United States of America; ${ }^{6}$ Spire Sciences, Boca Raton, United States of America; ${ }^{7}$ SetPoint Medical, Valencia, United States of America

Background: The inflammatory reflex plays a role in regulating innate and adaptive immunity through cellular and molecular pathways ${ }^{1}$. Activation of this neuroimmune reflex by electrical vagus nerve stimulation (VNS) reduced systemic inflammation and improved disease activity in a 17 subject rheumatoid arthritis (RA) proof-of-concept study using a reprogrammed epilepsy stimulator ${ }^{2}$. A novel miniaturized neurostimulator, the "MicroRegulator" (MR), was developed for a first-in-human pilot study in multi-drug refractory RA.

Objectives: To assess the safety and efficacy of the MR in a double-blind study in active RA patients.
Methods: The MR was implanted in 14 patients with active RA and prior insufficient response to $=2$ bDMARDS or JAK inhibitors with $=2$ different modes of action; all patients remained on stable background of methotrexate. Three weeks after implantation, the first 3 subjects were stimulated 1 min QD and, following safety review board approval, the remaining 11 patients were implanted with the MR and randomized to $1 \mathrm{~min}$ of sham, QD, or QID stimulations for 12 weeks. Patients, rheumatologists, joint assessors and monitors were fully blinded to treatment arm. Subjects randomized to sham had their devices activated after the primary endpoint at 12 weeks. Clinical efficacy was measured by DAS28-CRP response and contrast-enhanced MRI (RAMRIS OMERACT). The pharmacodynamic response to VNS was assessed in blood using cytokine production in an ex-vivo bioassay (TruCulture).

Results: 14 patients were enrolled (mean prior bDMARDs $=4.8$, mean DAS28$\mathrm{CRP}=5.94$ ). Implantation and stimulation were generally well tolerated. There were no device or treatment-related SAEs and 2 surgery related adverse events (left vocal cord paralysis, Horner's syndrome) that resolved without clinically significant sequelae. DAS28-CRP change at week 12 was (mean \pm SEM): Open label $\mathrm{QD}=-1.44 \pm 0.64, \mathrm{QD}=-1.24 \pm 0.88, \mathrm{QID}=0.38 \pm 0.71$, Sham $=0.16 \pm 0.21$ Of QD stimulated patients, 4 of 6 had a EULAR good or moderate response. MRI measures of synovitis or osteitis did not change after 12 weeks of stimulation. RAMRIS erosion scores correlated with EULAR response (change \pm SEM in ero sion scores in EULAR responders = $-2.2 \pm 1.4$ vs. $2.4 \pm 0.96$ in EULAR non-res ponders). The pharmacodynamic response to VNS was confirmed in actively stimulated groups with $>30 \%$ decrease from baseline in bioassay levels of IL- $1 \beta$, IL-6, and TNF-a at week 12.

Conclusion: The novel MR device and stimulation was well tolerated independent of the two surgery-related events. MR associated stimulation reduced signs and symptoms of RA in a meaningful number of highly drug-refractory subjects No clinical improvement was observed in the sham group. These initial pilot data support the use of the MR in a larger blinded sham-controlled study in patients who have failed biologics or targeted oral therapies as a novel approach for treatment of RA and other chronic inflammatory diseases.

\section{REFERENCES}

[1] Andersson U, Tracey K, Annu. Rev. Immunol. 2012; 30:313.

[2] Koopman, F, et. al. PNAS. 2016; 113(29):8284

Disclosure of Interests: Mark C. Genovese Grant/research support from: Sanofi/Genzyme, Genentech/Roche, RPharm, Consultant for: Sanofi/Genzyme, Genentech/Roche, RPharm, Norman Gaylis Grant/research support from: Multiple clinical research trials, BMS, AbbVie, GSK, Janssen, Amgen, Pfizer, Regeneron, UCB, Sanofi, SetPoint, ImmunPharma, Astra Zeneca, Sandoz, Novartis, Gilead, Consultant for: electroCore, David Sikes Grant/research support from: SetPoint MedicalPfizerActelionAbbvieEli Lilly, Alan Kivitz Shareholder of: Novartis, Consultant for: Abbvie, Janssen, Pfizer, UCB, Genzyme, Sanofi, Regeneron, Boehringer Ingelheim, Sun Pharma Advanced Research, Flexion., Paid instructor for: Celgene, Horizon, Merck, Novartis, Pfizer, Genzyme, Sanofi, Regeneron Speakers bureau: Celgene, Horizon, Merck and Genetech, Flexion, Diane M Horowitz Grant/research support from: SetPoint Medical, Charles Peterfy Shareholder of: Spire Sciences, Inc, Consultant for: AbbVie, Acerta, Amgen, AstraZeneca, Bris tol-Myers Squibb, Centrexion, Daiichi Sankyu, Five Prime Therapeutics, Genentech, Hoffmann-La Roche, Janssen, Lilly USA, Medlmmune, Merck, Novartis Plexxikon, Pfizer, Sanofi, Salix-Santarus, Samsung, Employee of: Spire Sciences, Inc, Speakers bureau: Amgen, Yaakov Levine Shareholder of: SetPoint Medical Employee of: SetPoint Medical, David Chernoff Shareholder of: SetPoint Medical, Consultant for: Crescendo BioScience, Employee of: SetPoint Medical DOI: 10.1136/annrheumdis-2019-eular.8716

\section{LB0010 ULTRA-LOW DOSES OF RITUXIMAB OR RETREATMENT OF RHEUMATOID ARTHRITIS: A RANDOMISED CONTROLLED NON-INFERIORITY TRIAL}

L.M. Verhoef ${ }^{1}$, Nathan den Broeder ${ }^{2}$, R.M. Thurlings ${ }^{3}$, W.H. van der Laan ${ }^{4}$, W. van der Weele ${ }^{5}$, Marc Kok ${ }^{5}$, H.J. Bernelot Moens ${ }^{5}$, Thasia Woodworth ${ }^{5}$, Bart van den Bemt ${ }^{6}$, Frank van den Hoogen ${ }^{5}$, Alfons den Broeder ${ }^{5} .{ }^{1}$ Sint Maartenskliniek, Rheumatology, Nijmegen, Netherlands; ${ }^{2}$ Radboudumc, Rheumatology, Nijmegen, Netherlands; ${ }^{3}$ Reade, Rheumatology, Amsterdam, Netherlands; ${ }^{4}$ Maasstad hospital, Department of Rheumatology and Clinical Immunology, Rotterdam, Netherlands; ${ }^{5}$ Ziekenhuisgroep Twente, Rheumatology, Almelo, Netherlands; ${ }^{6}$ David Geffen School of Medicine, University of California, Division of Rheumatology, Los Angeles, United States of America; ${ }^{7}$ Sint Maartenskliniek, Pharmacy, Nijmegen, Netherlands; ${ }^{8}$ Radboudumc, Pharmacy, Nijmegen, Netherlands

Background: Rituximab (RTX) is an effective treatment for patients with Rheu matoid Arthritis $(R A) .1000 \mathrm{mg}(1 \times 1000 \mathrm{mg}$ or $2 \times 500 \mathrm{mg})$ has similar 6 -month efficacy as the registered dose of $2 \times 1000 \mathrm{mg}$. Based on several case reports and a 